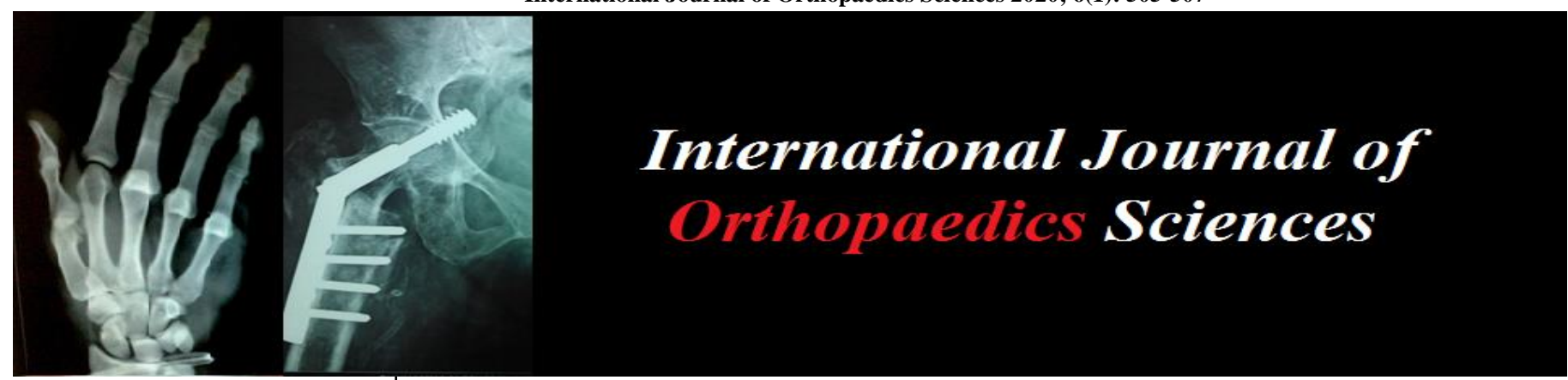

E-ISSN: 2395-1958

P-ISSN: 2706-6630

IJOS 2020; 6(1): 505-507

(C) 2020 IJOS

www.orthopaper.com

Received: 20-11-2019

Accepted: 24-12-2019

Dr. SU Shiva Prakash

Associate Professor, Department

of Orthopedics, East Point

College of Medical Sciences and

Research Centre, Bangalore,

Karnataka, India
Corresponding Author: Dr. SU Shiva Prakash

Associate Professor, Department of Orthopedics, East Point

College of Medical Sciences and

Research Centre, Bangalore,

Karnataka, India

\section{Clinical profile of patients with supracondylar fracture femur}

\section{Dr. SU Shiva Prakash}

DOI: $\underline{\text { https://doi.org/10.22271/ortho.2020.v6.i1i.1916 }}$

\section{Abstract}

The mechanism of injury for most supracondylar fractures is thought to be axial loading with varus, valgus, or rotational forces. A bimodal distribution of high-energy trauma in younger patients and lower energy in elderly patients is typically seen with these injuries. However, higher-energy injuries in elderly patients are not uncommon. In younger patients, supracondylar fractures often occur following highenergy trauma related to motor vehicle or motorcycle accidents. In these patients there may be considerable fracture displacement, comminution, open wounds, and soft tissue injuries. This was a prospective longitudinal observational study with a follow up period of 6 months to 18 months. After obtaining approval from institutional ethics committee, 30 skeletally mature patients with distal fracture femur fractures, satisfying the inclusion and exclusion criteria were enrolled. Informed and written consent was taken from the enrolled patients. Supracondylar fracture of right femur more commonly affected than left in this present study group. Supracondylar fracture of right femur was seen in 17 patients making up to $56.7 \%$ of fractures and left sided femur was seen in 13 patients accounting for $43.3 \%$ of the fractures. None had bilateral fractures.

Keywords: Supracondylar fracture femur, fracture displacement, clinical profile

\section{Introduction}

The supracondylar area of the femur is defined as the zone between the femoral condyles and the junction of the metaphysis with the femoral diaphysis. This comprises approximately the distal $15 \mathrm{~cm}$ of the femur, as measured from articular surface. It is important to distinguish extra-articular fractures from intercondylar as well as diaphyseal fractures of the distal femur because the methods of treatment and prognosis are considerably different ${ }^{[1]}$.

The mechanism of injury for most supracondylar fractures is thought to be axial loading with varus, valgus, or rotational forces. A bimodal distribution of high-energy trauma in younger patients and lower energy in elderly patients is typically seen with these injuries. However, higher-energy injuries in elderly patients are not uncommon. In younger patients, supracondylar fractures often occur following high-energy trauma related to motor vehicle or motorcycle accidents. In these patients there may be considerable fracture displacement, comminution, open wounds, and soft tissue injuries. On the other hand, in elderly osteoporotic patients, supracondylar fractures frequently occur after a ground level fall on a flexed knee. Notching of the anterior cortex of the distal femur while making femoral chamfer cuts during knee arthroplasty may predispose the distal femur to fracture ${ }^{[2,3]}$.

Predictable deformities occur after a distal femur fracture and are produced primarily by the direction of the initial fracture displacement and secondarily by the contraction of the thigh musculature. Spasm and irritability in the quadriceps, hamstrings, and adductors often lead to limb shortening with varus angulation at the fracture site. Muscle contraction of the gastrocnemius often produces an apex posterior angulation and displacement of the distal fragment. In fractures with intercondylar extension, soft tissue attachments to the respective femoral condyles tend to produce splaying and rotational malalignment of the condyles that contributes to joint incongruity ${ }^{[4]}$.

The OTA fracture classification was used in this study because it is easy to use and applicable to most parts of the skeleton. It distinguishes between extra-articular (type A), partial articular (type B), and complete articular (type C) injuries, and accounts for fracture complexity. 
A basic treatment plan for distal femur fractures usually can be formulated based on this classification system. Because of the large number of fracture patterns seen in clinical practice, however, some fractures do not fit neatly into any classification scheme. This emphasizes the fact that every patient must be individually evaluated and the - personalityll of the fracture must be considered in selecting the method of treatment.

\section{Methodology}

This was a prospective longitudinal observational study with a follow up period of 6 months to 18 months. After obtaining approval from institutional ethics committee, 30 skeletally mature patients with distal fracture femur fractures, satisfying the inclusion and exclusion criteria were enrolled. Informed and written consent was taken from the enrolled patients.

Data was obtained through structured questionnaires regarding the trauma, detailed clinical examination, relevant investigations, and entered in the case record form (CRF).

\section{Inclusion criteria}

- Patients with supracondylar fracture femur Type A and Type C.

- Patients of age above 18 years and attained complete skeletal maturation.

- Closed supracondylar fracture femur.

- Open supracondylar fracture femur with GustiloAnderson type I, II and IIIA.

\section{Exclusion criteria}

- Supracondylar femoral fractures with neurovascular compromise.

- Patients with OTA Type B fractures of distal femur.

- Patients with open grade 1llB \& 1llC distal femur fractures (Gustilo-Anderson classification).

- Patients with any fracture other than the distal fracture femur in the ipsilateral limb.

- Patients with pathological distal femoral fractures other than osteoporosis.

\section{Results}

Table 1: Age distribution of patients in this study

\begin{tabular}{|c|c|c|}
\hline Age & Number of Patients & Percentage (\%) \\
\hline $21-30$ & 9 & 30 \\
\hline $31-40$ & 10 & 33.3 \\
\hline $41-50$ & 3 & 10 \\
\hline $51-60$ & 4 & 13.3 \\
\hline Above 60 & 4 & 13.3 \\
\hline
\end{tabular}

Age of the patients ranged from 21 to $71 y$ rs with an average age of 41.9 years. Majority of the patients $(63.3 \%)$ were in the age group of 21-40 years. Male patients were aged between 21-61 years with an average of 37.8 years. Female patients were aged between 30-71 years with average of 49.7 years.

Table 2: Sex distribution in present study

\begin{tabular}{|c|c|c|}
\hline Sex & Number of Patients & Percentage (\%) \\
\hline Male & 19 & 63.3 \\
\hline Female & 11 & 36.7 \\
\hline
\end{tabular}

Out of 30 patients treated with locking compression plate, 19 $(63.3 \%)$ were male patients and $11(36.7 \%)$ were female patients.
Table 3: Nature of injury in present study

\begin{tabular}{|c|c|c|}
\hline Nature of Injury & Distal Femur Fractures & Percentage (\%) \\
\hline Rta & 22 & 73.3 \\
\hline Fall & 8 & 26.7 \\
\hline Total & 30 & 100 \\
\hline
\end{tabular}

In this study group $22(73.3 \%)$ fractures were sustained due to road traffic accidents and $8(26.7 \%)$ fractures are due to slip or fall from height.

Table 4: Side affected in present study

\begin{tabular}{|c|c|c|}
\hline Side & Number of Fractures & Percentage (\%) \\
\hline Right & 17 & 56.7 \\
\hline Left & 13 & 43.3 \\
\hline
\end{tabular}

Supracondylar fracture of right femur more commonly affected than left in this present study group. Supracondylar fracture of right femur was seen in 17 patients making up to $56.7 \%$ of fractures and left sided femur was seen in 13 patients accounting for $43.3 \%$ of the fractures. None had bilateral fractures.

Table 5: Relation between age and nature of injury in present study

\begin{tabular}{|c|c|c|c|c|}
\hline & RTA & & Fall & \\
\hline Age (years) & Number Of & Percent & Number Of & Percent \\
\hline & Patients & $\mathbf{( \% )}$ & Patients & $\mathbf{( \% )}$ \\
\hline$\leq 50$ & 19 & 63.3 & 3 & 10 \\
\hline$>50$ & 3 & 10 & 5 & 16.7 \\
\hline Total & 22 & 73.3 & 8 & 26.7 \\
\hline
\end{tabular}

In this study majority of the cases $19(63.3 \%)$ were due to road traffic accidents seen in below 50 years of age, whereas fractures due to ground level fall on flexed knee $16.7 \%$ ( 5 cases) seen in above 50 years of age.

Table 6: Type of injury in present study

\begin{tabular}{|c|c|c|}
\hline Type of Injury & Number of Fractures & Percentage (\%) \\
\hline Open & 19 & 63.3 \\
\hline Closed & 11 & 36.7 \\
\hline
\end{tabular}

Out of 30 fractures, 19 fractures accounting for $63.3 \%$ were open fractures. Rest of the fractures were closed.

\section{Discussion}

In the present study age of the patients ranged from 21 to 71 years with an average age of 41.9 years. Of these majority of the cases $19(63.3 \%)$ were in the age group of 21-40. The present study does not show biphasic age distribution of the patient population as observed in other studies. High energy trauma in $73.3 \%$ of our patients of which most of whom were younger.

In Yeap et al. (2007) study, patients ranged from 15 to 85 years with a mean age of 44 years ${ }^{[5]}$.

In Mongkon Luechoowong, 2008 study the mean age was 41.6 years ${ }^{[6]}$.

In Bachu S et al. (2017) study, patients ranged from 20-75 years with median age of 40 years ${ }^{[7]}$.

The sex distribution of the subjects revealed that, $19(63.3 \%)$ were males and $11(36.7 \%)$ were females. The reason for the disproportion being, male patients were more involved in outdoor activities than females hence, more prone to vehicular accidents and trauma ${ }^{[8]}$.

In our study $22(73.3 \%)$ patients sustained fractures due to road traffic accidents and $8(26.7 \%)$ by slip and fall. Among the patients who had RTA majority were below the age of 50 years and among those due to fall, majority were elderly. Young male patients had more RTA than females, as males go for outdoor activities than female so more prone for 
vehicular accidents.

Among 30 fractures, majority 19 (63.3\%) sustained open injuries. Among 19 open fractures: Gustilo-Anderson Type-1 were 12 , Type- 2 were 5 and Type-3A were 2 .

According to the OTA supracondylar fracture femur classification, intra articular (type C) fractures were seen in 17 (56.7\%) patients and rest $13(43.3 \%)$ had extra articular (type A) fractures. This indicates that type $\mathrm{C}$ fractures occur more than type A.

\section{Conclusion}

- Among 30 patients, 19 males and 11 were females, highest number of patients were in their $3^{\text {rd }}$ and $4^{\text {th }}$ decade $(63.3 \%)$.

- Road traffic accident was the most common mode of injury $(73.3 \%)$. There was not a single case with bilateral fractures.

- Most of the patients, reported within $1^{\text {st }}$ week of injury to the hospital.

- OTA, Type C2 fracture was the most common. 7 (23.4\%) out of 30 patients.

\section{References}

1. Martinet O, Cordey J, Harder Y, Maier A, Buhler M, Barraud G. The epidemiology of fractures of the distal femur Injury. 2000; 31(3):C62-3.

2. Areneson TJ, Melton LJ, Lewallen DG et al. Epidemiology of diaphyseal and distal femoral fractures in Rochester, Minnesota, 1965-1984. Clin Orthop Relat Res. 1988; 234:188-94.

3. Schutz M, Muller M, Krettek C et al. Minimally invasive fracture stabilization of distal femoral fractures with the LISS: A prospective multicentre study. Results of a clinical study with special emphasis on difficult cases. Injury 2001; 3(2):SC48-4.

4. Ayaz Khan M, Shafique M, Sahibzada AS, Sultan S. Management of type-A supracondylar fractures of femur with dynamic condylar screw (DCS). Journal of Medical Sciences. 2006; 14(1):44-7.

5. Yeap EJ, Deepak AS. Distal Femoral Locking Compression Plate Fixation in Distal Femoral Fractures: Early Results. Malaysian Orthopaedic Journal. 2007; 1(1):12-17.

6. Luechoowong M. The Locking Compression Plate (LCP) for Distal Femoral Fractures. Buddhachinaraj Medical Journal. 2008; 25:1.

7. Bachu S, Ramulu L. A study of surgical management of distal femoral fractures in adults using locking compression plate. Int J Res Orthop. 2017; 3(2):253-58.

8. Ayers ME, Iorio R, Healy WL. In: Scott R, Bono J, eds. Periprosthetic Fractures after Total Knee Arthroplasty in Revision Total Knee Arthroplasty. New York: Springer, 2005. 